\title{
Modulation of the Intracellular Cystine Content of Cystinotic Fibroblasts by Extracellular Albumin
}

\author{
JESS G. THOENE ${ }^{(15,)}$ AND ROSEMARY LEMONS \\ Department of Pediatrics and (ommunicahle Diseases, University of Michigan Medical School. Ann Arhor. Michigan. \\ USA
}

\begin{abstract}
Summary
Cystinotic fibroblasts contain highly elevated amounts of intraellular non-protein cystine within lysosomes compared to normal ibroblasts. Both the rate of cystine reaccumulation by cystinelepleted cystinotic fibroblasts and the steady-state cystine content if nondepleted cystinotic fibroblasts can be modulated by the Iddition of bovine serum albumin to the culture medium. This ffect is not seen in cultures of normal and cystinotic heterozygote ibroblasts. The eystinotic homozygote cells accumulate cystine Inder these conditions from proteolysis of the albumin. An inreased rate of pinocytosis or proteolysis of albumin does not iccount for the observed cystine accumulation by the cystinotic ibroblasts. Comparison of the amount of cystine accumulated to he amount of albumin degraded shows that less than one percent of the cystine moieties released by proteolysis is retained within hese cells.
\end{abstract}

\section{Speculation}

The metabolic defect leading to cystine storage in cystinosis remains to be identified. Study of the relationship between the rate of cystine accumulation and the cystine and cysteine content of proteins degraded by cystinotic fibroblasts may help to determine if the defect is related to an abnormality of lysosomal disulfide reduction.

Nephropathic cystinosis is an autosomal recessive condition which results in the intralysosomal storage of the disulfide amino acid cystine in most body tissues (8). The cause of the intralysosomal cystine accumulation is not known: however. the demonstration that cystine storage occurs in tibroblasts cultured from patients with cystinosis (7) has permitted in vitro investigation into the metabolic derangement in this condition. We have previously shown that treatment of cystinotic fibroblasts with cysteamine produces rapid and complete cystine depletion (10). Study of cystine-depleted cystinotic fibroblasts incubated in cystine-free medium showed that cystine reaccumulates under these condition. to about $30^{\prime}$; of control levels from the degradation of endogenous protein (11). The current report presents data which demonstrate that cystinotic fibroblasts can also accumulate cystine from the degradation of extracellular cystine-containing protein.

\section{MATERIALS AND MITHODS}

Skin fibroblasts derived from patients with nephropathic cystinosis and obligate heterozygotes were established in culture and maintained as previously described (10). Fibroblasts from normal control individuals were obtained from the Human Genetic Mutant Cell Repository. A modified Ham's F-12 medium was prepared without cystine and supplemented with $100^{\prime \prime} ;$ dialyzed fetal bovine serum (cystine-free medium). Complete medium contained $133 \mu \mathrm{M}$ I-cystine and was supplemented with nondialyzed fetal bovine serum.

Cells were harvested by trypsinization after washing twice in phosphate-buffered saline (PBS). Cell number was determined by a Coulter counter model ZF. and protein was determined colorimetrically with bovine serum albumin (BSA) as the standard (3). The intracellular nonprotein cystine content of fibroblasts was measured by a cystine binding protein assay (5). Cystine-depleted cystinotic fibroblasts were prepared by incubation for one hr in I mM cysteamine (10).

(ystine accumulation experiments were performed by adding test proteins to cystine-depleted cultures prepared as described. Reduced, reoxidized BSA was prepared by incubating a solution of BSA $(50 \mathrm{mg} / \mathrm{ml})$ in $1.6 \mathrm{mM}$ dithiothreitol (DTT) at $\mathrm{pH} 8.5$ under $\mathrm{N}$. for $2 \mathrm{hr}$ at $37^{\circ} \mathrm{C}$. The solution was then dialyzed under room air for $48 \mathrm{hr}$ against $0.01 \mathrm{M}$ Tris buffer $(\mathrm{pH} 8.5)$ at $4^{\circ} \mathrm{C}$ and finally dialyzed against cystine-free medium for $24 \mathrm{hr}$. A control BSA solution was prepared identically except that DTT was omitted.

Cysteamine and horseradish peroxidase type II (HRP) were obtained from Sigma Chemical ( ${ }^{\circ} \mathrm{O}$. $\mathrm{Na}^{12} \mathrm{I}$ was purchased from Amersham/Searle Corp. BSA was supplied by Armour Pharmaceutical Corp. All other reagents were of the best available grade. Radio-iodination of BSA was accomplished by the chloramine-T method (4). The specific activity of the I-labeled BSA was 3.15 $\times 10^{\circ} \mathrm{cpm} / \mathrm{mg}$ and was $98.2 \%$, acid precipitable. To measure the rate of degradation of BSA. cells were incubated in medium containing labeled BSA, and the increase in total $6 " ;$ sulfosalicylic acid-soluble radioactivity present in the medium was determined at each time point. All procedures were done in duplicate. To ensure that iodination had not produced significant denaturation of the protein. the circular dichroism spectrum of native and iodinated BSA was determined. Both spectra showed a single trough at $230 \mathrm{~nm}$, and the molar ellipticities were the same within the limits of experimental error.

The rate of pinocytosis was determined by incubating cell cultures in complete medium containing $\operatorname{HRP}(1 \mathrm{mg} / \mathrm{ml})(9)$. At harvest. each plate was washed 4 times in PBS. incubated an additional 30 min in complete medium lacking HRP. and washed twice in PBS, and the cells were removed from the plate with trypsin and subjected to sonic disruption in $0.3 \mathrm{ml}$ of distilled water. The intracellular HRP content was measured using the odianisidine method (9)

\section{RESUI.TS}

Table 1 shows the effect of BSA supplementation in cystinefree medium on the intracellular nonprotein cystine content of normal. cystinotic heterozygote. and cystinotic fibroblasts. The cystinotic cells double their intracellular cystine content within 24 $\mathrm{hr}$ : the other cell types do not demonstrate significant increases in intracellular cystine content. However, all three cell types survive in this medium for periods of 4 to 14 days. Such cells incubated in cystine-free medium lacking BSA supplementation become detached in 24 to $48 \mathrm{hr}$.

Figure 1 shows the effect of the addition of various amounts of BSA and fetal bovine serum on the rate of cystine accumulation by cystine-depleted cystinotic fibroblasts. The data are expressed 
Table I. The accumulation of crstine hy fibroblasts incuhated in cistine-free medium supplemented with $B S A(50) \mathrm{mg} / \mathrm{ml})^{l}$

Intracellular non-protein cystine content (nmol/10" cells)

$$
\text { (ell type }
$$

Normal

Cystinotic heterozygote

(ystinotic homozygote

$\begin{array}{lllll}0 \mathrm{hr} & 24 \mathrm{hr} & 48 \mathrm{hr} & 60 \mathrm{hr} & \frac{72 \mathrm{hr}}{3} \\ 0.16 & 0.25 & 0.11 & & 0.11 \\ 0.18 & 0.22 & & 0.30 & \\ 3.56 & 7.85 & & 7.93 & \end{array}$

${ }^{1}$ The BSA was added to non-cystine-depleted fibroblast cultures, the cells were harvested at the times indicated, and the intracellular nonprotein cystine content was determined. See text for details. The data represent the mean cystine content determined from 3 experiments using 2 normal cell lines: 2 experiments using 1 heterozygote cell line and 1 experiment using 1 homozygote cell line.

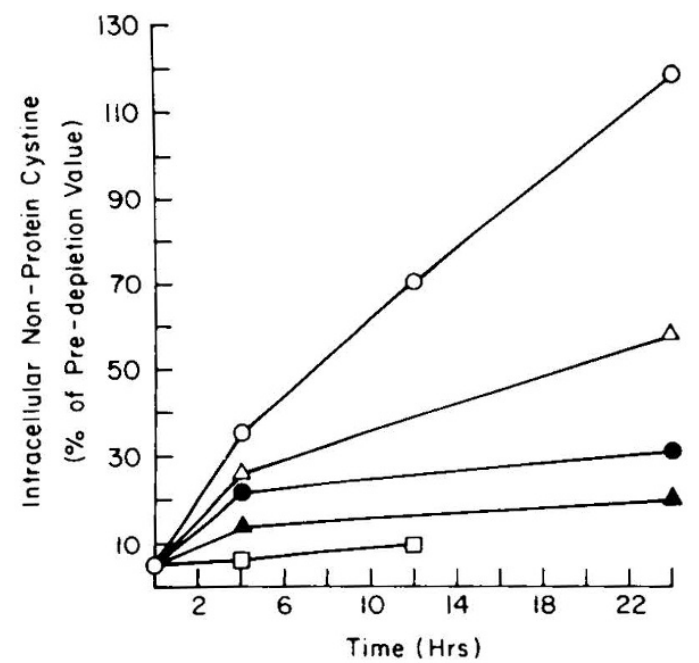

Fig. 1. The effect of BSA on the rate of eystine reaccumulation by cystine-depleted cystinotic tibroblasts. BSA $(50 \mathrm{mg} / \mathrm{ml}): \triangle$. BSA $(25$ $\mathrm{mg} / \mathrm{ml})$ : no BSA: П. BSA $(50 \mathrm{mg} / \mathrm{ml})$ and $(00) \mu \mathrm{M}$ chloroquine. All of the preceeding were supplemented with $10{ }^{\prime}$; dialyzed fetal calf serum. $\Delta$. n.. BSA 1.0; dialyed fetal call serum. Data are expressed as a percentage of initial (predepletion) cystine content. This value was $1.8 \pm 0.2$ nmoles cystine per $10{ }^{\prime \prime}$ cells. Points. mean of duplicate plates. Similar data were obtained in two cystinotic cell lines.

as a percentage of predepletion cystine content to facilitate comparison between experiments. The rate of cystine accumulation varies with the amount of BSA present in the medium. Addition of $100 \mu \mathrm{M}$ chloroquine to medium supplemented with BSA (50) $\mathrm{mg} / \mathrm{ml}$ ) abolished cystine accumulation. The fetal calf serum used contained BSA $(15 \mathrm{mg} / \mathrm{ml})$; reduction of the serum content from 10 to $1 \%$ in the absence of BSA further reduced the rate of cystine accumulation. Measurement of the nonprotein cystine content of the cystine-free medium supplemented with BSA $(50 \mathrm{mg} / \mathrm{ml})$ showed no increase in cystine content: $0.22 \mu \mathrm{M}$ initially and 0.18 $\mu \mathrm{M}$ at $24 \mathrm{hr}$.

To ascertain if the enhanced rate of cystine accumulation observed in Figure I was due to the cystine content of the BSA and not due either to (1) a nonspecific effect due to the high concentration of exogenous protein in solution. or (2) the presence of exogenous cystine moieties associated with the BSA. experiments were performed using gelatin, a cystine-free protein. and BSA which had been subjected to disulfide reduction by dithiothreitol to remove exogenous disulfides. The amount of cystine accumulation observed at $24 \mathrm{hr}$ in cells incubated with gelatin $(25$ $\mathrm{mg} / \mathrm{ml}$ ) was $34 \%$ of the initial value. This was comparable to that observed in cells incubated in cystine-free medium with $10 \%$ dialyzed fetal calf serum lacking BSA (30\%" of initial value) (Fig. 1). Incubation of cystine-depleted cells in BSA which had been subjected to prior reduction and reoxidation did not result in a significant diminution in the amount of cystine accumulation produced. At $24 \mathrm{hr}$, the cells incubated in control BSA mediun $\left(20 \mathrm{mg} / \mathrm{ml}\right.$ ) accumulated 1.02 nmole cystine per $10^{\mathrm{t}}$ cells, wherea: those incubated in reduced. reoxidized BSA $(20 \mathrm{mg} / \mathrm{ml})$ accumulated 0.97 nmole cystine per $10^{6}$ cells.

To determine if an excessive rate of pinocytosis could be relatec to the cystine accumulation in cystinotic cells, this function was measured using HRP. The rate of pinocytosis as measured by the uptake of HRP was not greater in the cystinotic cells than in normal cells. Normal cells took up HRP at a rate of $26.4 \mathrm{ng} / 10^{*}$ cells $/ \mathrm{hr}$, and cystinotic cells took up HRP at a rate of $17.0 \mathrm{ng} / 10^{\prime}$ cells/hr.

To determine if an excessive rate of degradation of BSA was responsible for the cystine accumulation observed in cystinotic tibroblasts, the rate of degradation of ${ }^{12}$ I-labeled BSA was measured in cultures of normal and cystinotic fibroblasts. The results are shown in Table 2 and Figure 2. There is a close correlation between the amount of BSA degraded and the amount of cystine accumulated by cystinotic fibroblasts: however. normal cells do not accumulate cystine regardless of the amount of BSA degraded. Cystinotic cells accumulate cystine even when BSA degradation proceeds at a rate one-fifth that of normal cells.

\section{DISC USSION}

Cystinosis is an unusual example of lysosomal storage disease in that the retained material. cystine, is an end product of the degradation process rather than a large, partially digested precursor. The cause for the retention of cystine within lysosomes of cystinotic tissue is not known; however, proteolysis may be a $\mathrm{m}$ :jor source of the stored cystine. Accumulating evidence has demonstrated that lysosomes are active in the proteolysis of cellular and extracellular proteins, and the amino acids produced by this process form a nonequilibrating subcellular compartment (12). Study of the subcellular distribution of valine in perfused rat liver demonstrated that $40 \%$ of total intracellular valine was

Table 2. The degradation of I-labeled BSA by cultures of normal and cystinotic fibroblasts ${ }^{\prime}$

Time (hr)

BSA degradation Intracellular cystine ( $m g / t)^{\prime}$ (c)lls) (mom) $/ 10)^{x}$ cells)

\begin{tabular}{ccccc} 
Time (hr) & Normal & $\begin{array}{c}-- \\
\text { Cystin- } \\
\text { otic }\end{array}$ & Normal & $\begin{array}{r}\text { Cystin- } \\
\text { otic }\end{array}$ \\
4 (after cysteamine) & & & 0.07 & 0.03 \\
24 & 0.15 & 0.03 & 0.06 & 0.12 \\
& 0.92 & 0.16 & 0.09 & 0.40 \\
\hline
\end{tabular}

' See text for details of method. These results were found in 2 cystinotic and 2 normal cell lines.

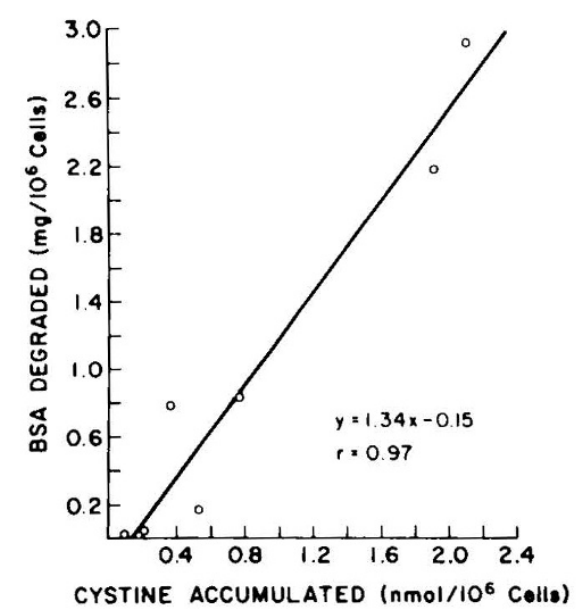

Fig. 2. The relationship between the degradation of ${ }^{15}$-labeled BSA and cystine accumulation by cystinotic fibroblasts. Similar data were obtained in two cystinotic cell lines. 
esent in the lysosomal and mitochondrial fraction and was rived from protein degradation (12). It has been suggested that ilure of the protein-derived intralysosomal amino acid pool to uilibrate with the cytosol is due to a transport mechanism within e lysosomal membrane (12). No data have yet been presented to aracterize the properties of the proposed lysosomal transport stem, and data on the relative distribution of cystine in subcellar fractions of normal tissue are lacking. It is known that the nino acid content of the granular fraction of cystinotic leukocytes not different from normal for any amino acid except cystine (8). Cystinotic fibroblasts have been shown to accumulate cystine om the degradation of cellular protein (11). The current report smonstrates that a disulfide-containing extracellular protein can so contribute to the lysosomal cystine pool. The addition of SA, which contains 17 moles of cystine and 0.4 mole of cysteine ir mole of protein, to cultures of normal, cystinotic heterozygote ad cystinotic homozygote cells in cystine-free medium results in doubling of the cystine content of the cystinotic cells, but no lange in the normal and heterozygous cells (Table 1). This bservation suggests that cystinotic cells degrade BSA within sosomes following pinocytosis and then retain some fraction of ie cystine released via proteolysis. The observation that all three :ll types can survive for periods of several days in cystine-free tedium supplemented with BSA suggests that the cystine released ia proteolysis of the BSA can be used for protein synthesis. The ossibility of utilization of degradation products of extracellular Iacromolecules by cells under stepdown conditions has been reviously raised (9). If this is true, then in these experiments the tilization of cystine was apparently directly from lysosomes to re site of protein synthesis because the nonprotein cystine content $f$ the medium supplemented with BSA $(50 \mathrm{mg} / \mathrm{ml})$ did not Icrease after $24 \mathrm{hr}$ incubation.

The rate of cystine accumulation in BSA-supplemented medium $y$ cystine-depleted cystinotic fibroblasts is dependent on the oncentration of BSA in the medium (Fig. 1). Addition of $100 \mu \mathrm{M}$ hloroquine to medium containing BSA $(50 \mathrm{mg} / \mathrm{ml})$ results in no ystine accumulation. This further supports the lysosomal charcter of the proteolysis because chloroquine has been shown to ahibit intralysosomal proteolysis (13) and also to inhibit the ccumulation of cystine from the degradation of cellular protein 11).

To further establish the relationship between the degradation if BSA by cultures of cystinotic fibroblasts and the accumulation if cystine, studies using radio-iodinated BSA were performed. able 2 shows the degradation of ${ }^{125}$ I-labeled BSA by both normal nd cystinotic fibroblasts. The amount of protein degraded per nillion cells is greater in the normal than in the cystinotic fibrolasts; however, only the cystinotic fibroblasts accumulate cystine. 3ecause the rate of degradation of extracellular protein is depenlent upon a number of uncontrolled variables $(1,2)$, no conclusion an be drawn from these data regarding the relative rate of xtracellular protein degradation by normal and cystinotic fibrolasts. However, an excessive rate of protein degradation by the :ystinotic fibroblasts cannot account for the cystine accumulation ecause the cystinotic fibroblasts accumulated cystine while de,rading protein at a slower rate than the normal cells which did lot accumulate cystine. This finding was further substantiated by neasuring the rate of pinocytosis using HRP. Previous study of he uptake and degradation of macromolecules in solution by sultured cells has shown pinocytosis to be the rate-limiting step 6). Thus, an abnormally rapid rate of pinocytosis of extracellular proteins by the cystinotic cells could conceivably lead to cystine accumulation by overwhelming the lysosomal egress mechanism with cystine derived from proteolysis. The results of the current study show that pinocytosis is not greater in cystinotic fibroblasts than in normal fibroblasts.

The relationship between BSA degradation and cystine accumulation in cystinotic fibroblasts is shown in Figure 2. The data are taken from experiments using two cystinotic cell lines and two BSA concentrations. A close correlation between BSA degradation and cystine reaccumulation is seen $(r=0.97)$. Previous work has shown that lysosomes degrade BSA to single amino acids (6). By comparing the amount of cystine accumulated to the number of cystine moieties presumably released via proteolysis $(1 \mathrm{mg}$ BSA contains 260 nmoles of cystine), it is possible to calculate that the cystinotic cells in these studies retained 0.003 cystine moieties for each cystine moiety released by proteolysis. This ratio has been obtained in four separate experiments using two cystinotic cell lines. It would appear to indicate that the cystine accumulation may be the result of a system which is only marginally defective. This could explain the difficulty experienced in previous attempts to delineate the defect.

The data presented in this report demonstrate that cystinotic fibroblasts can accumulate cystine from the degradation of extracellular, cystine-containing proteins. Comparison of the rates of pinocytosis and proteolysis of extracellular proteins by normal and cystinotic cells does not indicate that these processes are directly involved in producing the abnormal cystine storage: however, the current demonstration that the rate of cystine accumulation by cystinotic cells can be modulated by the concentration of BSA in the culture medium may provide an effective tool for further investigation. It has been previously suggested that cystine storage in this condition is due to a defective intralysosomal disulfide reductase; however, direct evidence to support this hypothesis is lacking. Study of the amount of cystine accumulation produced by proteins in the disulfide and sulfhydryl state may yield indirect evidence regarding this possibility. Such studies are in progress.

\section{REFERENCES AND NOTES}

1. Dice, J. F., and (ioldherg. A. L.: Structural properties of rat serum proteins which correlate with degradative rates in vivo. Nature (Lond.). 262: 514 (1976)

2. Kaplan. J.: Modulation of lysosomal enzyme levels in cultured cells. Effects of alterations in cell density, balanced growth. and endocytosis. Arch. Biochem Biophys, 187: 376 (1978)

3. Lowry. O. 11., Rosebrough. N. J.. Farr. A. L., and Randall, R. J.: Protein measurement with the Folin phenol reagent. J. Biol. Chem., 19.3: 265 (1951)

4. M.C (inahey, P. J.. and Dixon, F. J.: A method of trace iodination of proteins for immunologic studies. Int. Arch. Allergy Appl. Immunol.. 24: 185 (1966).

5. Oshima, R. G., Willis, R. C., Furlong, (. E.. and Schneider, J. A.. Binding assays for amino acids: the utilization of a cystine binding protein from Escherichic coli for the determination of acid-soluble cystine in small physiological samples. J. Biol. Chem.. 249: 6033 (1974).

6. Pratten. M. K.. Williams. K. E.. and Lloyd, J. B.: A quantitative study of pinocytosis and intracellular proteolysis in rat peritoneal macrophages. Biochem. J., /68: 365 (1977).

7. Schneider, J. A., Rosenbloom, F. M. Bradley, K. H., and Seegmiller, J. E. Increased free cystine content of fibroblasts cultured from patients with cystinosis. Biochem. Biophys. Res. Commun., 29: 527 (1967)

x. Schulman, J. D. and Bradley, K. H.: In vitro studies on cystinosis. In: J. D) Schulman: Cystinosis, (hap. X. (United States Government Printing Office. Washington. D. ('.. 1972)

9. Steinman. R. M. Silver, J. M., and cohn. Z. A.: Pinocytosis in fibroblasts. Quantitative studies in vitro. J. ('ell Biol.. 0.3: 949 (1974).

10. Thoene, J. G. Oshima. R. G.. Crawhall, J. C., Olson, D. L.. and Schneider, J. A (ystinosis: intracellular cystine depletion by aminothiols in vitro and in vivo. J. (lin. Invest.. 58: $180(1976)$

11. Thoene, J. (j., Oshima, R. G., Ritchie, D. G.. and Schneider. J. A.: Cystinotic tibroblasts accumulate cystine from intracellular protein degradation. Proc. Natl. Acad. Sci. U. S. A., 74: 4505 (1977).

12. Wad. W. F . and Mortumere, (i. I... Compartmentation of intracellular amino acids in rat lives: evidence for an intralysosomal pool derived from protein degredation. J. Biol. ('hem., 25.3: 3581 (1978).

13. Wibo, M. and Poole. B.: Protein degradation in cultured cells. II. The uptake of chloroquine by rat fibroblasts and the inhibition of cellular protein degradation and cathepsine B. J. Cell. Biol., 6.3: 430 (1974)

14. The authors thank Dr. Jerry Schneider for the gift of the cystine binding protein and Dr. Jules Shafer for assistance with the circular dichroism spectra.

15. Requests for reprints should be addressed to: J. G. Thoene. M.D.. Kresge II. R6028. Department of Pediatrics and Communicable Diseases, University of Michigan Medical School. Ann Arbor. MI 48109 (USA)

16. This research was supported by the Michigan Department of Mental Health and the Biomedical Research Support (jrant. University of Michigan

17. Received for publication May 29, 1979

18. Accepted for publication August 14. 1979 